Journal of Engineering and Applied Sciences 14 (8): 2707-2715, 2019

ISSN: 1816-949X

(C) Medwell Journals, 2019

\title{
MPPT using PSO Algorithm for PV System Supplying Outdoor BTS
}

\author{
Nada Tarik Abdul Jabar and Anas Lateef Mahmood \\ Department of Electronic and Communications Engineering, College of Engineering, \\ Al-Nahrain University, Baghdad, Iraq
}

\begin{abstract}
The problem of continued power outages in Iraq which has been going on for more than 30 years is making it difficult to provide energy to BTS. The best alternative solution to providing electricity to these areas is through the use of stand-alone solar energy systems. In this study, the PSO algorithm was used for the purpose of finding the Maximum Power Point (MPP) of a proposed stand-alone solar energy system to supply power to the mobile BTS used in Iraq. Through field visits to some BTS in various mobile phone companies operating in Iraq such as Zain, Umniah and Huawei it is show that there are no alternative systems to supply electricity to these towers in the case of main power interruption except the rely on diesel generators. Some simple solar energy systems were found in these companies to charge the batteries for the outdoor BTS to ensure the continuity of electricity to the BTS but just for a few minutes until the operation of diesel generator which causes known problems such as environmental pollution and noise. The proposed system contains from solar panels, buck-boost converter and the tracking algorithm to provide power to a BTS, the system was simulated for different partial shading conditions using MATLAB 2017 a package for two systems $1560 \mathrm{~W}$ and $18 \mathrm{~kW}$. The PSO algorithm shows good results in maximum power point tacking for the proposed stand-alone solar energy system, especially, in the case of partial shading in contrast to the P\&O method which shows its failure some times to find the maximum power point. The results shows that the PSO method is better and faster than the $\mathrm{P} \& \mathrm{O}$ method in the case of partial shading in case of small power system $(1560 \mathrm{~W})$ while for large power system $(18765 \mathrm{~W})$ the results proved that PSO was able to reach the MPP at high accuracy but slower than in small systems in case of partial shading.
\end{abstract}

Key words: MPPT, PSO, BTS, stand-alone, photovoltaic, renewable energy, PV system

\section{INTRODUCTION}

In rural areas where there are no traditional transmission line and electrical network, the renewable energy sources become the best alternative. In addition, they have the advantages of clean energy with no $\mathrm{CO}_{2}$ and other unhealthy emission (Goud and Kalpana, 2007). Solar cells are connected in series and parallel arrangement on a hard surface to form a panel that panel had specified voltage and current rating. Now in a large PV system, the panels are also connected in series and parallel fashion to get desired voltage and current. The irradiation on the PV panel is largely affected by shading because of surrounding building, dust on the PV panel and trees. As the PV current mainly depends on the irradiation, the cell/ panels which are connected in series and undergo partial shading may get burn our due the forceful flow of current by cell/panel which is connected in series with it. To bypass the excessive current a diode is connected in parallel with the solar PV cell/panel. Due to the nonlinear characteristics of the PV curve and because of partial shading on the panel this results in multiple peaks which add complexity to the nonlinear PV curve. To get a maximum power point there are many Heuristics algorithms have been published like PSO method that represents an optimum solution for the case of partial shading (Talukder, 2011; Belghith et al., 2016). The MPPT controller is the most important part of the system. It is responsible to track the maximum power point in the past many algorithms used to track the power like $\mathrm{P} \& \mathrm{O}$ (Kamran et al., 2018) incremental conductance (Khaliq and Mahmood, 2015) and some of these method modified to improve the result or to minimize the sensor (Eldahab et al., 2017). In this study we compare between two MPPT methods ( $\mathrm{EO}$ and PSO) optimization controller to tracking the maximum power point accurately and rapidly in response.

Unfortunately, utility grids in Iraq are not sustained and subject to severe problems which lead to interrupt the service. Presently, the power demands exceed the

Corresponding Author: Nada Tarik Abdul Jabar, Department of Electronic and Communications Engineering, 


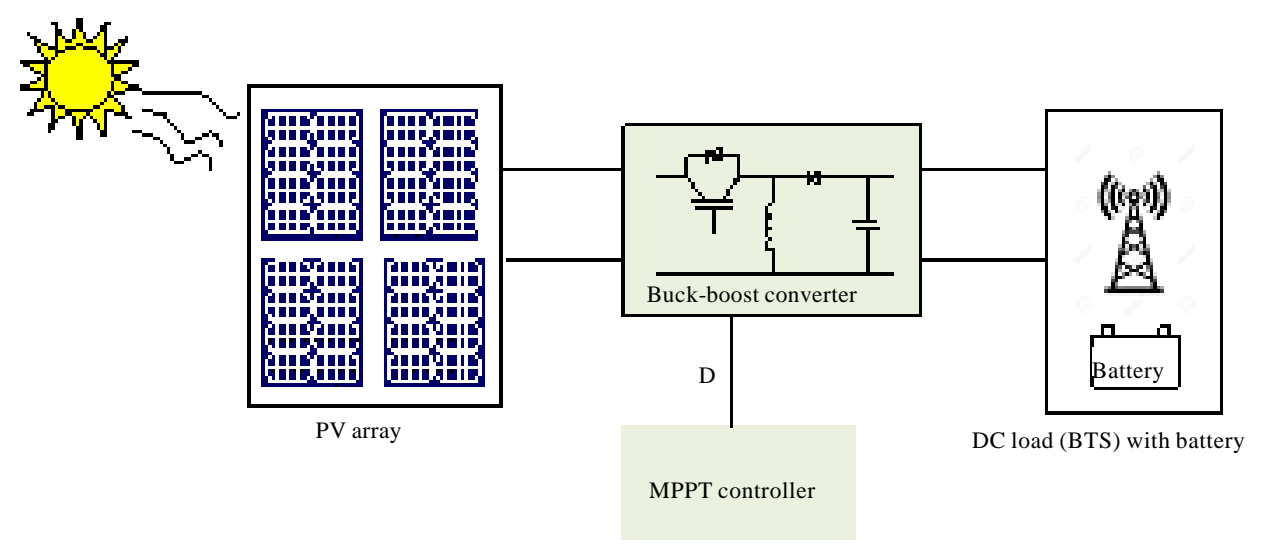

Fig. 1: Stand-alone PV system for BTS

generation capacity, hence, renewable energy sources to supply such applications are indispensable. Telecommunication Towers (BTS) used in this research for mobile communication supplied from PV source is considered the optimum solution for ensuring the sustainability of the tower services. The purpose of the solar solution in telecom towers application is to reduce the dependency on diesel generators and deliver reliable power in regions where the grid is unreliable or nonexistent. Several off-grid telecom towers were powered by running Diesel Generators (DGs) thus operating at consuming more fuel and shortening the life of the DG (Goud and Kalpana, 2007). In addition, the longer run-times of the DG implied frequent maintenance and high associated costs. For these reasons, the need of having renewable energy sources becomes very essential.

Stand-alone PV system for BTS: The stand-alone PV solar system that used to supply power to BTS is shown in Fig. 1. It consists of photovoltaic array, DC-DC converter, MPPT controller which is based on $\mathrm{P} \& \mathrm{O}$ and PSO tracking algorithms. There are 2 types of BTS indoor and outdoor, for example, the DBS3900 is an outdoor BTS from Hawaii Telecom Company. The outdoor BTS needs less power than indoor type because it uses fans for cooling purposes it had simple and higher integration structure. Example for the indoor model is BTS3900 and BTS3900L and for the outdoor model is BTS3900A. The cabinet macro base station is installed with the RFU in centralized mode. The cabinet macro base station is applicable to a centralized installation scenario. The BTS3900 and BTS3900L are used for the indoor centralized installation scenario while the BTS3900A is used for the outdoor centralized installation scenario and it used 2 RRU units on the tower. This RRU unit transmits power for calls with the subscribers and we can control on
Table 1: Measured currents of BTS at Al-Mansour Asia cell site in Baghdad BTS equipment $\quad$ Measured DC current (A) RRU 6-12

Microwave link $\quad 2-5$

Upper fan 4

$\underline{\text { Door fan }}$

the consumption power by decrease or increase the range of the power according to calls and coverage area. The main important unit in the BTS is the RRU unit that transmits power to received call by subscribers as shown in Table 1.

The information listed in Table 1 were measured at site Al-Mansour for Asia cell in Baghdad and this region is crowded by the citizens, so, the RRU unit draw large currents while in rural area the power consumption will be less because the number of citizens are small. In this study the design of the stand-alone PV system is considered for rural area and according to Hossam et al. (2016) the BTS for rural area needs $2700 \mathrm{~W}$ for outdoor unit.

\section{MATERIALS AND METHODS}

\section{MPPT controller}

P\&O tracking method: The advantage of this algorithm is the simplicity of implementation and it has very low cost (Selmi et al., 2014). In this method the current and voltage of the PV are measured and based on the variation in power as regard to the variation in voltage, the direction of movement is decided. And the voltage is either increased or decreased steeply until reaching to the MPP at which the $\mathrm{dp} / \mathrm{dv}=0$. The flow chart of the process is charted in Fig. 2, the selected parameters for the $\mathrm{P} \& \mathrm{O}$ MPPT algorithm in this work are shown in Table 2 and (Fig. 3).

PSO tracking method: This algorithm starts with an initial group of random particles (solutions) and updating of 


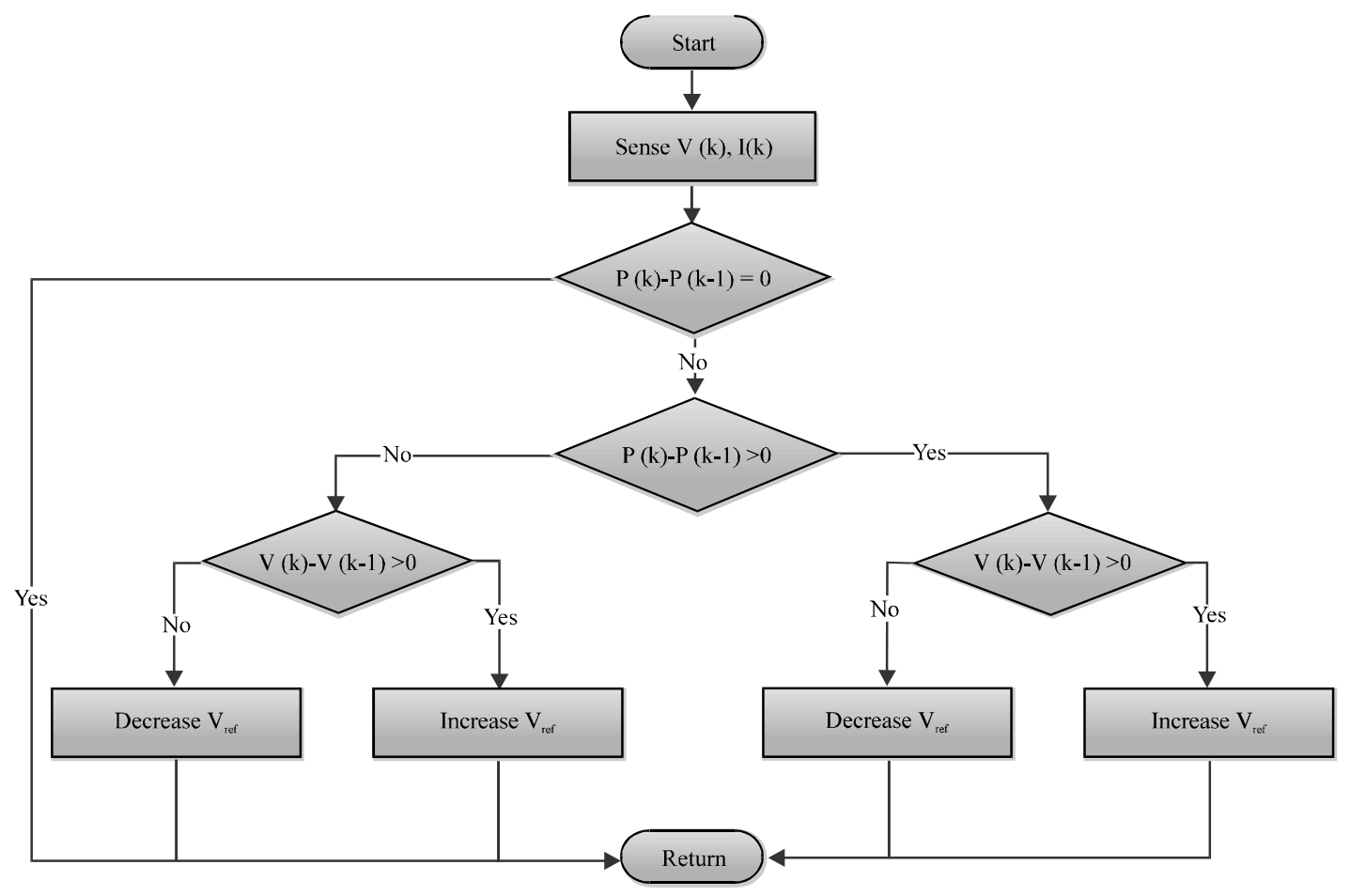

Fig. 2: $\mathrm{P} \& \mathrm{O}$ flowchart

Table 2: Parameters of the P\&O MPPT algorithm

Parameters

Duty cycle initial value

Step size duty cycle

Duty cycle maximum

Duty cycle minimum

generations is continuing until reach to the optimum solution. There is a fitness of each individual which is measured frequently to select the fittest individual to continue with the next generation. Every individual has two values the first is the personal best or the local best and the second is the global best. The local best is for each individual a while the global best is only one over all the populations. The algorithm can be summarized as follow each particle tries to modify its current position and velocity based on the distance between its present position and the personal best and the distance between its current location and the global best. The process starts with finding the nearest point to the MPP by the PSO optimization, the duty cycle represents the position and the power represents the fitness function. Figure 3 shows the PSO flowchart. The following equations were used for determining the new location and velocity for the PSO (Clerc and Kennedy, 2002):

$$
\begin{aligned}
& \mathrm{V}_{\mathrm{i}}(\mathrm{t}+1)=\mathrm{W} \times \mathrm{V}_{\mathrm{i}}(\mathrm{t})+\mathrm{C} 1 \times\left(\mathrm{P}_{\mathrm{i}}(\mathrm{t})-\left(\mathrm{X}_{\mathrm{i}}(\mathrm{t})\right)+\right. \\
& \mathrm{C} 2 \times\left(\mathrm{g}(\mathrm{t})-\mathrm{X}_{\mathrm{i}}(\mathrm{t})\right)
\end{aligned}
$$

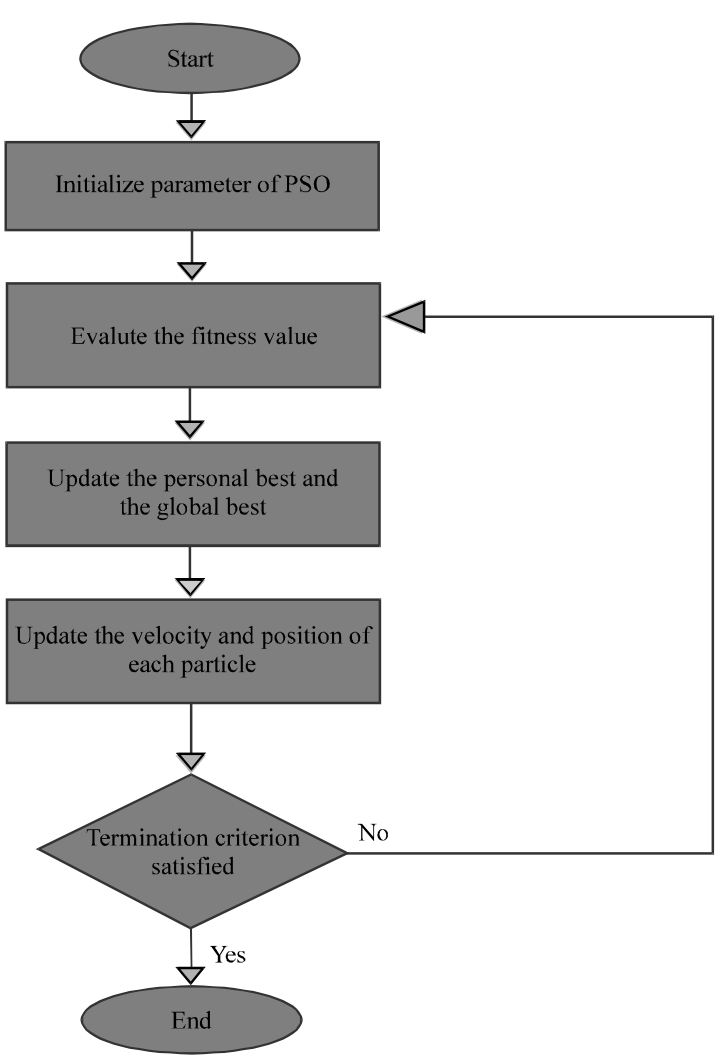

Fig. 3: PSO flowchart 
Table 3: Parameters of the PSO MPPT algorithm

\begin{tabular}{lc}
\hline Parameters & Values \\
\hline No. of iterations & 10.0 \\
C1 and C2 & 2.0 \\
Maximum duty cycle & 0.9 \\
Minimum duty cycle & 0.2 \\
W & 1.0 \\
\hline
\end{tabular}

$$
V_{i}(t+1)=X_{i}(t)+V_{i}(t+1)
$$

Where:

$\mathrm{X}_{\mathrm{i}}(\mathrm{t}) \quad=$ Particle swarm on the curve

$\mathrm{V}_{\mathrm{i}}(\mathrm{t}) \quad=$ The velocity of the particle on the curve

$\mathrm{W} \quad=$ Inertia weight of velocity

$\mathrm{C} 1$ and $\mathrm{C} 2=$ Acceleration factors

The selected parameters for the PSO MPPT algorithm in this research are shown in Table 3.

\section{RESULTS AND DISCUSSION}

Buck-boost converter: The converter include DC input Voltage source $\left(V_{s}\right)$, inductor $(\mathrm{L})$, diode, filter Capacitor (C), controlled Switch (S) and load Resistance (R) as shown in Fig. 4. The output voltage of the buck-boost:

$$
V_{0}=-\frac{D}{1-D} V_{S}
$$

The output voltage $V_{0}$ is negative with respect to the ground and its value magnitude can be smaller or greater than the input voltage and when the Duty cycle (D) equal to $(0.5)$ the voltage in input equal in magnitude the voltage in output. The switch in the converter used to control by the methods to control on the extraction of the power design the converter according to Kazimierczuk (2008), Goetzberger and Hoffmann (2005). The value of the inductor is given by:

$$
\mathrm{L}_{\mathrm{b}} \geq \frac{(1-\mathrm{D})^{2}}{2 \mathrm{f}} \mathrm{R}
$$

While the value of the capacitor can be obtain by:

$$
C_{\min }=\frac{D V_{0}}{V_{r} R f}
$$

where $v_{r}$ and $f$ are the voltage ripple and switching frequency. Table 4 shows the parameter values of the buck-boost converter where it is assumed here that $\mathrm{V}_{\mathrm{O}}=$ 48 for BTS and $V_{\mathrm{r}}=0.02 \mathrm{~V}$.

PV sizing: In order to determine the amount of the required power supplied by stand-alone solar energy

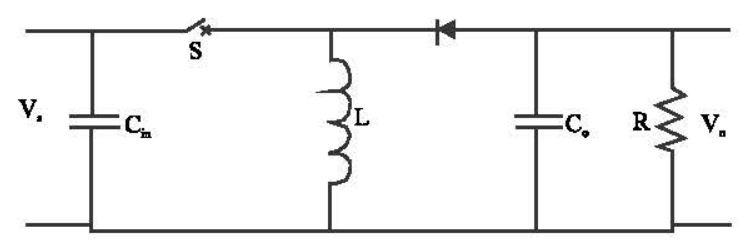

Fig. 4: Buck-boost converter

Table 4: Parameters of the buck-boost converter

\begin{tabular}{lc}
\hline Parameters & Values \\
\hline $\mathrm{L}$ & $1.5 \mu \mathrm{H}$ \\
Output $\mathrm{C}_{O}$ & $20 \mathrm{mF}$ \\
Input $\mathrm{C}_{\text {in }}$ & $3.5 \mathrm{mF}$ \\
Switching frequency f & $2.5 \mathrm{kHz}$ \\
Resistor (load) & $0.1228 \Omega$ \\
\hline
\end{tabular}

Table 5: Specifications of the PV panel

PV panel module

LGelectronics LG260SIC-A3

Maximum power

$260.618 \mathrm{~W}$

Open circuit voltage

Short circuit current

$38.1 \mathrm{~V}$

Maximum voltage

$9.05 \mathrm{~A}$

Maximum current

$31.1 \mathrm{~V}$

system for outdoor BTS the economic calculations by Hossam et al. (2016) will be taken here in this study. These power calculations show that the PV panels power needed to supply an outdoor BTS with $2700 \mathrm{~W}$ and batteries used to feed the system at night time in addition to the presence of the external DG used in the cloudy days only is equal to $18 \mathrm{~kW}$. LG electronics LG260S1C-A3 PV panel was used in the simulation of the proposed system, the specifications of this panel are shown in Table 5.

The total PV power for the proposed tracking system which supplies an outdoor BTS is assumed equal to 18765 $\mathrm{W}$ to achieve this large amount of power a 72 panel are needed with $260.618 \mathrm{~W}$ for each panel. It is found that the simulation of this large number of panels using MATLAB program is difficult if the total number of panels are connected together unless it is divided into 4 groups each group contains 18 panels ( 3 series $\times 6$ parallel), so, the full and partial shading were applied to a small group contains 6 panels $(3 \times 2)$ have $1560 \mathrm{~W}$ power and then to the overall $18765 \mathrm{~W}$ system. The effect of partial shading is so clear if the numbers of panels are small while in large systems the effect was less, however, even the tracking algorithms were better compared for small systems (Fig. 6 and 7).

MPPT for $1560 \mathrm{~W}$ load: In this study the P\&O and PSO algorithms were applied to track the maximum power point or the global power for $(3 \times 2)$ panels with $1560 \mathrm{~W}$ total power at $25^{\circ} \mathrm{C}$ but under different partial shading 

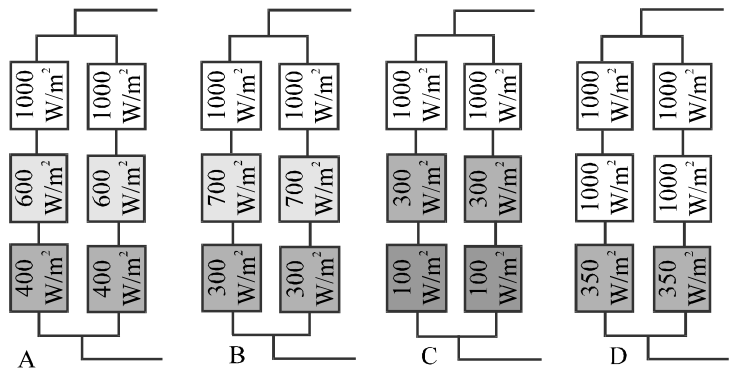

Fig. 5: Different partial shading cases

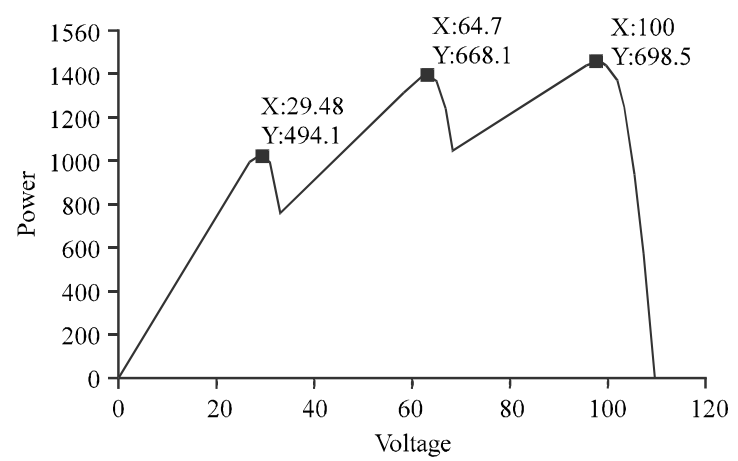

Fig. 6: P-V characteristic for case A; Photovoltaic module characteristics curve

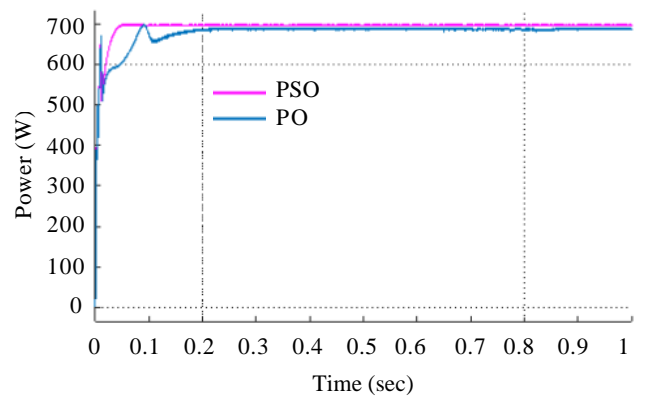

Fig. 7: $\mathrm{PSO}$ and $\mathrm{P} \& \mathrm{O}$ methods for case $\mathrm{A}$

positions on the panels. As mentioned that the cause of choosing this small number of panels is to show the performance of the tracking methods better than in large number of panels and also to reduce the simulation time. Different cases were taken for partial shading in order to examine the $\mathrm{P} \& \mathrm{O}$ and $\mathrm{PSO}$ tracking algorithms as shown in Fig. 5.

Case A: In this case it is assumed that the solar irradiations on the 6 panels are as shown in Fig. 5 (A) and the P-V characteristic is shown in Fig. 6. When the $\mathrm{P} \& \mathrm{O}$ and $\mathrm{PSO}$ tracking algorithms are applied on the PV system to find the MPP individually it is seen that both methods found the MPP successfully as shown in Fig. 7

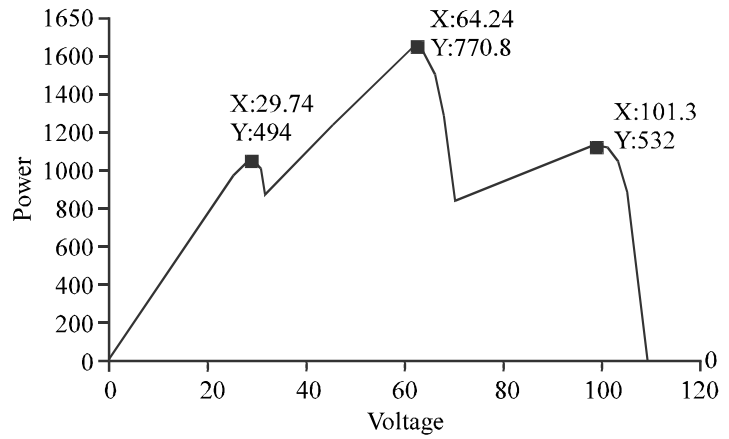

Fig. 8: P-V characteristic for case B; Photovoltaic module characteristics curve

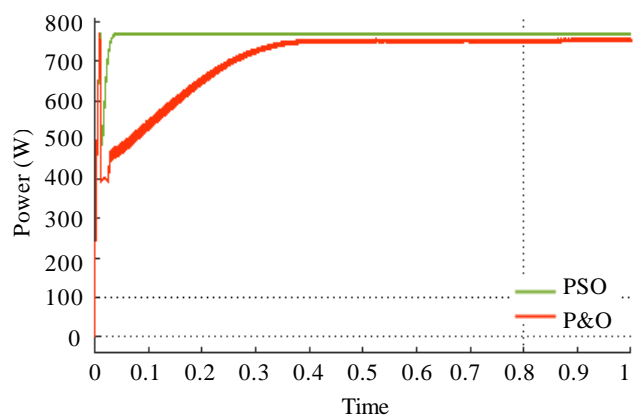

Fig. 9: $\mathrm{PSO}$ and $\mathrm{P} \& \mathrm{O}$ methods for case $\mathrm{B}$

but it is clear from the figure that the PSO found the MPP faster and more accurate than the P\&O.

Case B: In this case it is assumed that the solar irradiations on the 6 panels are as shown in Fig. 5 (B) and the $\mathrm{P}-\mathrm{V}$ characteristic is shown in Fig. 8. It is clear from the figure that the global peak power is now located in the middle between two local values. For the second time the PSO tracking algorithm found this global power point quickly and accurately while the $\mathrm{P} \& \mathrm{O}$ took a long time to reach this in addition to the perturbation at the starting as shown in Fig. 9.

Case C: In this case it is assumed that the solar irradiations on the 6 panels are as shown in Fig. $5(\mathrm{C})$ and the $\mathrm{P}-\mathrm{V}$ characteristic is shown in Fig. 10. When the $\mathrm{P} \& \mathrm{O}$ and PSO tracking algorithms are applied on the PV system to find the MPP individually it is seen that the P\&O method failed in founding the global power point and it track the local power point while the PSO algorithm found the global power point successfully as shown in Fig. 11.

Case D: In this case it is assumed that the solar irradiations on the 6 panels are as shown in Fig. 5 (D) and 


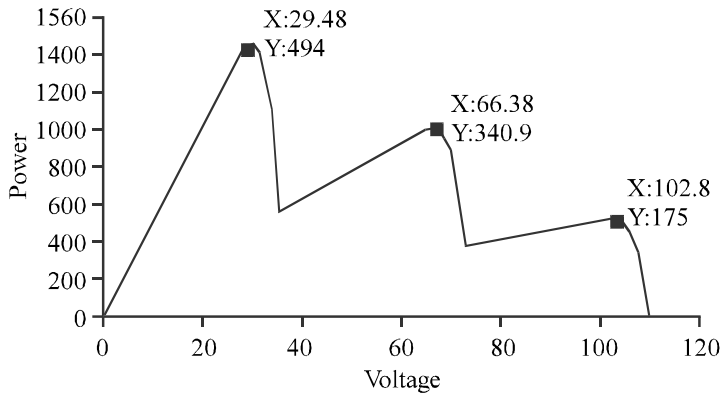

Fig. 10: P-V characteristic for case C; Photovoltaic module characteristics curve

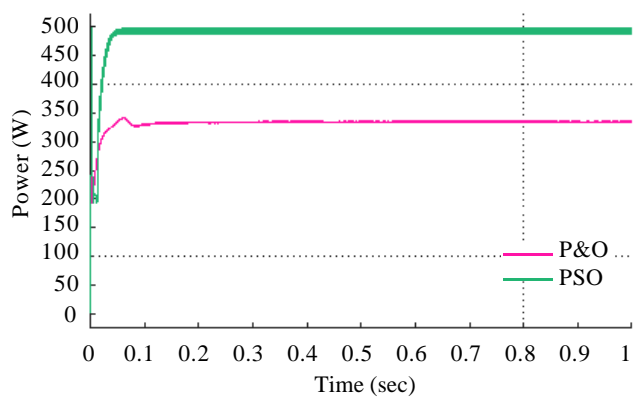

Fig. 11: $\mathrm{PSO}$ and $\mathrm{P} \& O$ methods for case $\mathrm{C}$

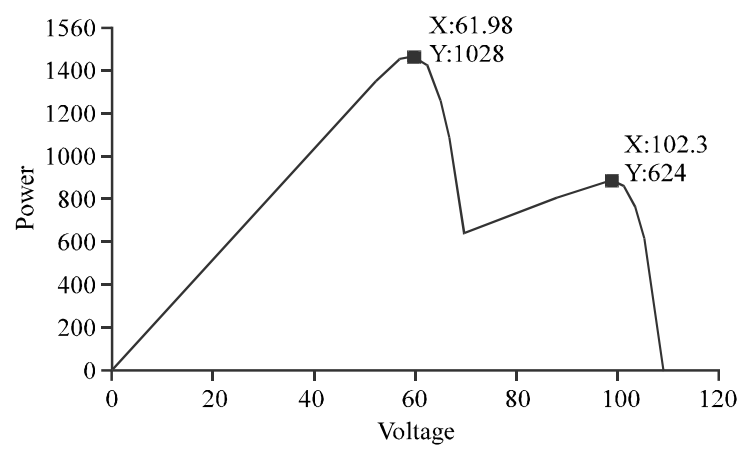

Fig. 12: P-V characteristic for case D; Photovoltaic module characteristics curve

the $\mathrm{P}-\mathrm{V}$ characteristic is shown in Fig. 12. When the $\mathrm{P} \& \mathrm{O}$ and PSO tracking algorithms are applied on the PV system to find the MPP individually it is seen that the P\&O method failed in founding the global power point and it track the local power point while the PSO algorithm found the global power point successfully as shown in Fig. 13. However, Table 6 shows a summary of the main results for the 4 cases including power and duty cycle when the PSO and $\mathrm{P} \& \mathrm{O}$ tracking algorithms were applied.

MPPT for $18670 \mathrm{~W}$ load: In order to find the maximum power point MPP produce by an 18670 stand-alone solar

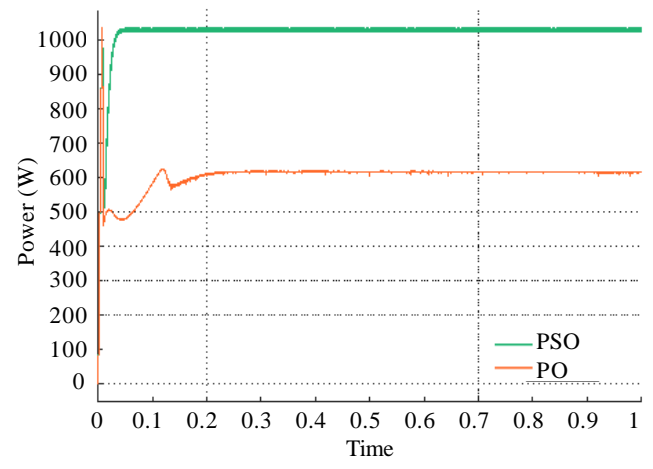

Fig. 13: $\mathrm{PSO}$ and $\mathrm{P} \& O$ methods for case D

energy system for outdoor BTS under partial shading effect. The 72 PV panels were divided into 4 groups each group contained $18 \mathrm{PV}$ panels as shown in Fig. 14. The $\mathrm{P} \& \mathrm{O}$ and $\mathrm{PSO}$ tracking algorithms were applied to the Simulink Model shown in Fig. 15. The irradiance was changed to 3 different values to perform the partial shading effect and in each case the tracking algorithms were calculated the MPP. The main results that obtained were the load power, ripple or oscillation of the load power and at last a summarized table was given including the obtained power values in addition to the duty cycle values for each tracking algorithm.

Case 1: In this case it is assumed that the solar irradiations on the first group are changed as shown in Fig. 16 while the irradiations on the three other groups are equal to $1000 \mathrm{~W} / \mathrm{m}^{2}$. The $\mathrm{P}-\mathrm{V}$ characteristic is shown in Fig. 17. The P\&O and PSO tracking algorithms were applied individually on the PV system shown in Fig. 15 to find the MPP, the PV power for the two algorithms were drawn as shown in Fig. 18. It is clear from the figure that the tracking performance of the PSO algorithm is better than $\mathrm{P} \& \mathrm{O}$.

Case 2: In this case, the first group was given a non uniform solar irradiance values $\left(1000-700-100 \mathrm{~W} / \mathrm{m}^{2}\right)$ as shown in Fig. 19 while the irradiance on the other 3 groups are $1000 \mathrm{~W} / \mathrm{m}^{2}$. The $\mathrm{P}-\mathrm{V}$ characteristic is shown in Fig. 20 and it is also clear that the system response for the $\mathrm{PSO}$ algorithm in MPPT is better than $\mathrm{P} \& \mathrm{O}$ algorithm in addition, the power extracted from the PSO is higher than P\&O. Both algorithms became slower and took along running time in large power system.

Case 3: In this case, the solar irradiations were changed for the first 3 groups of the PV system with different irradiance values as shown in Fig. 21. The P-V characteristic is shown in Fig. 22. From Fig. 23, it is clear 


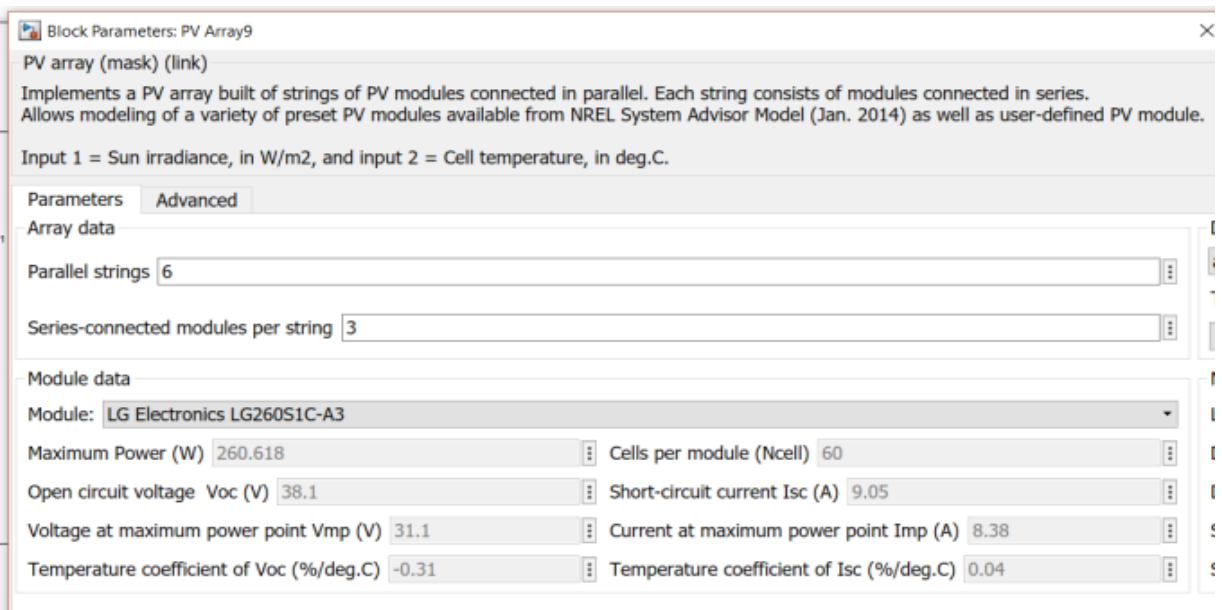

Fig. 14: PV panels group specifications

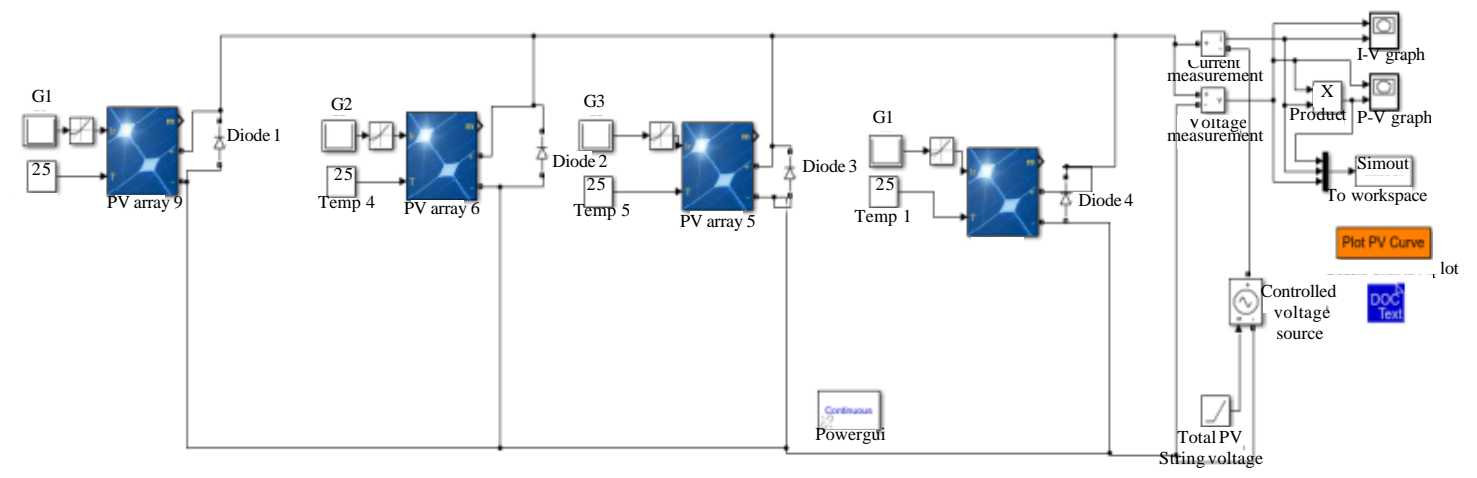

Fig. 15: Simulink Model of the PV system

\begin{tabular}{|c|c|c|c|c|c|}
\hline \multicolumn{7}{|c|}{ Group 1 } \\
\hline 1000 & 1000 & 1000 & 1000 & 1000 & 1000 \\
\hline 1000 & 1000 & 1000 & 1000 & 1000 & 1000 \\
\hline 350 & 350 & 350 & 350 & 350 & 350 \\
\hline
\end{tabular}

Fig. 16: Solar irradiations in $\mathrm{W} / \mathrm{m}^{2}$
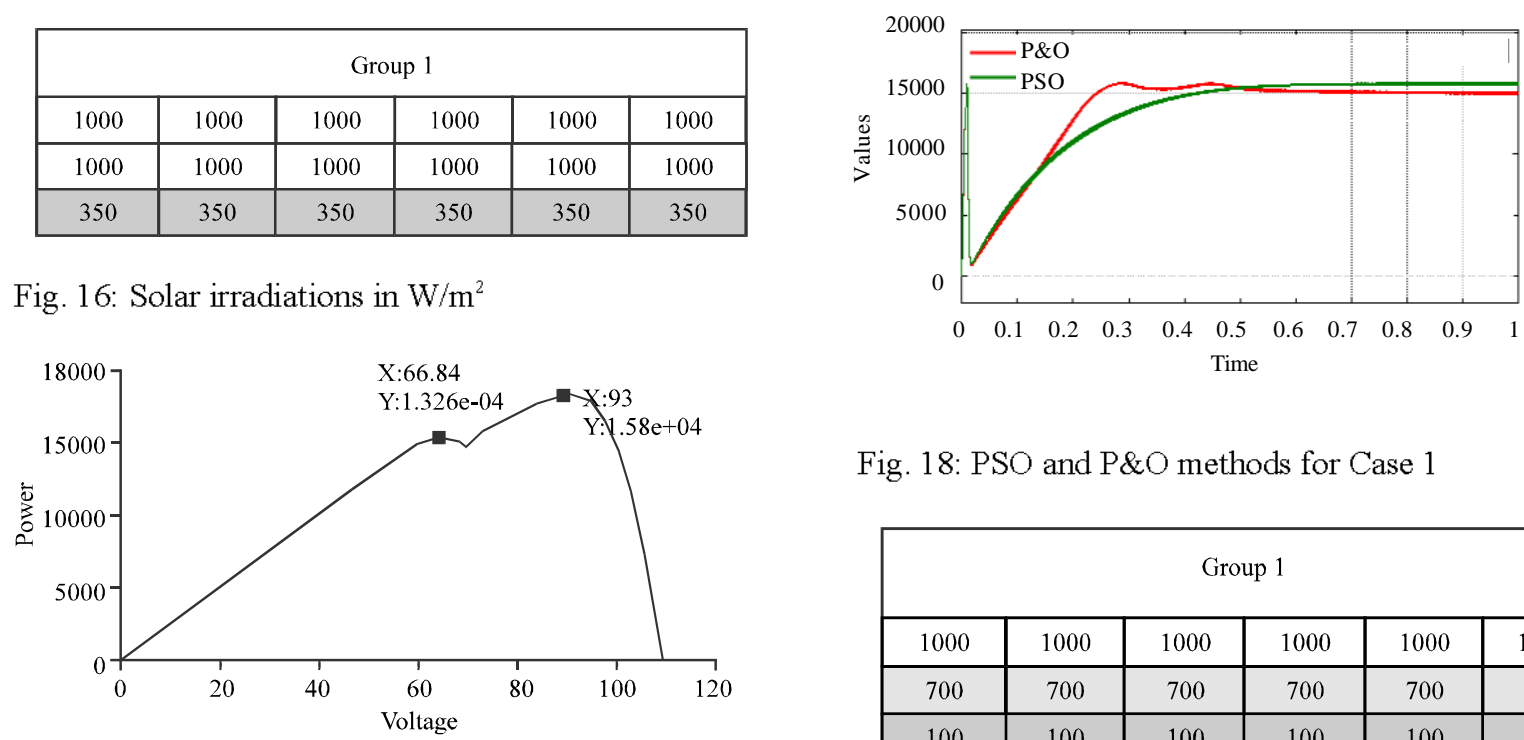

Fig. 18: $\mathrm{PSO}$ and $\mathrm{P} \& \mathrm{O}$ methods for Case 1

\begin{tabular}{|c|c|c|c|c|c|}
\hline \multicolumn{7}{|c|}{ Group 1 } \\
\hline 1000 & 1000 & 1000 & 1000 & 1000 & 1000 \\
\hline 700 & 700 & 700 & 700 & 700 & 700 \\
\hline 100 & 100 & 100 & 100 & 100 & 100 \\
\hline
\end{tabular}

Fig. 17: P-V characteristic for case 1; Photovoltaic module characteristics curve

Fig. 19: Solar irradiations in $\mathrm{W} / \mathrm{m}^{2}$ 


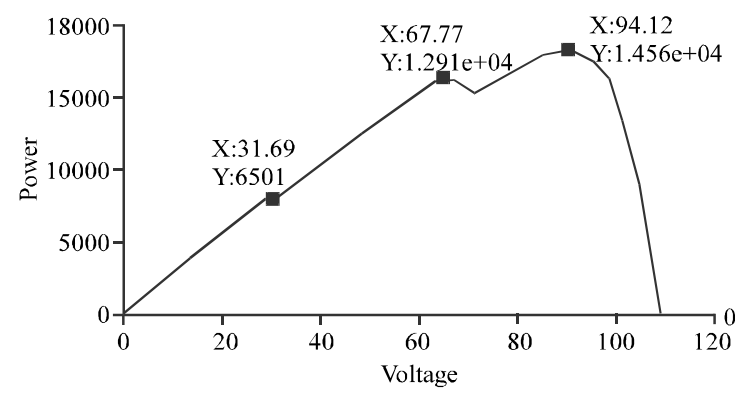

Fig. 20: P-V characteristic for case 2; Photovoltaic module characteristics curve

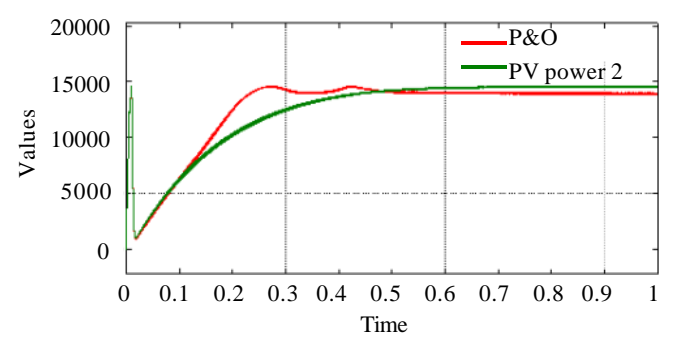

Fig. 21: $\mathrm{PSO}$ and $\mathrm{P} \& \mathrm{O}$ methods for case 2

\begin{tabular}{|c|c|c|c|c|c|}
\hline \multicolumn{6}{|c|}{ Group 1 } \\
\hline 1000 & 1000 & 1000 & 1000 & 1000 & 1000 \\
\hline 600 & 600 & 600 & 600 & 600 & 600 \\
\hline 400 & 400 & 400 & 400 & 400 & 400 \\
\hline
\end{tabular}

\begin{tabular}{|l|l|l|l|l|l|}
\hline \multicolumn{6}{|c|}{ Group 2 } \\
\hline 500 & 500 & 500 & 500 & 500 & 500 \\
\hline 500 & 500 & 500 & 500 & 500 & 500 \\
\hline 500 & 500 & 500 & 500 & 500 & 500 \\
\hline
\end{tabular}

\begin{tabular}{|l|l|l|l|l|l|}
\hline \multicolumn{5}{|c|}{ Group 2 } \\
\hline 500 & 500 & 500 & 500 & 500 & 500 \\
\hline 500 & 500 & 500 & 500 & 500 & 500 \\
\hline 500 & 500 & 500 & 500 & 500 & 500 \\
\hline
\end{tabular}

Fig. 22: Solar irradiations in $\mathrm{W} / \mathrm{m}^{2}$

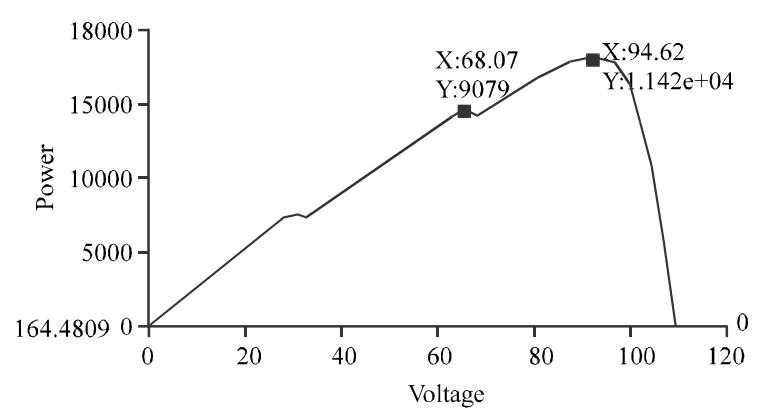

Fig. 23: P-V characteristic for case 3; Photovoltaic module characteristics curve

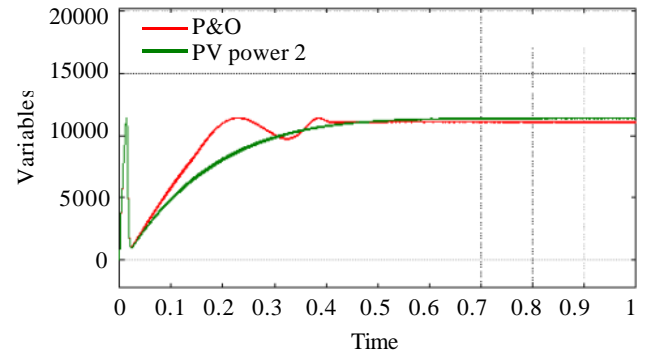

Fig. 24: $\mathrm{PSO}$ and $\mathrm{P} \& \mathrm{O}$ methods for case 3

Table 6: PSO vs. P\&O results $1560 \mathrm{~W}$ system

\begin{tabular}{|c|c|c|c|c|}
\hline \multirow[b]{2}{*}{ Shading } & \multicolumn{2}{|l|}{$\mathrm{P} \& \mathrm{O}$} & \multicolumn{2}{|l|}{ PSO } \\
\hline & Power (W) & Duty & Power (W) & Duty \\
\hline Case A & 688.5 & 0.256 & 697.2 & 0.260 \\
\hline Case B & 757.5 & 0.359 & 770.3 & 0.369 \\
\hline Case C & 335.0 & 0.268 & 492.2 & 0.503 \\
\hline Case D & 617.0 & 0.242 & 1027.0 & 0.411 \\
\hline \multicolumn{5}{|c|}{ Table 7: PSO vs. P\&O results $18670 \mathrm{~W}$ system } \\
\hline \multirow[b]{2}{*}{ Shading } & \multicolumn{2}{|l|}{$\mathrm{P} \& \mathrm{O}$} & \multicolumn{2}{|l|}{ PSO } \\
\hline & Power (W) & Duty & Power (W) & Duty \\
\hline Case 1 & 15010 & 0.256 & 15790 & 0.324 \\
\hline Case 2 & 13920 & 0.298 & 14558 & 0.315 \\
\hline Case 3 & 11090 & 0.272 & 11418 & 0.286 \\
\hline
\end{tabular}

that the $\mathrm{P} \& \mathrm{O}$ had large oscillation at the beginning while the PSO is stable and accurate more. Table 6 and 7 gives summary to the main results obtained from the 3 cases. In the previous three cases the PSO record higher power than the $\mathrm{P} \& \mathrm{O}$ with less ripple values (Fig. 14-24).

\section{CONCLUSION}

The BTS in rural areas that have no stable energy sources like the grid supply need to have a renewable PV energy source as alternative power source. These alternative sources affected by the weather conditions like solar irradiations and temperature also the shading detorate the power obtained by this PV system. Therefore a good controller and optimizer are needed to maximize the extracted energy from this renewable energy source. Based on this conclusion, the $\mathrm{P} \& \mathrm{O}$ and PSO tracking algorithms have been tested in this research. The system has been modeled by using MATLAB Simulink 2017a. The system simulates different partial shading cases under $\mathrm{P} \& \mathrm{O}$ and $\mathrm{PSO}$ tracking algorithms. The results show that, the system is valid and working correctly and able to follow the reference power. Furthermore, the output results of all modes of operation have been 
compared to show the improvements. The results prove that, the PSO system reaches to the reference power faster in case of $\mathrm{P} \& O$ method in small system while in large system the PSO. In large power systems $\mathrm{P} \& \mathrm{O}$ tracking algorithm shows better performance than in small power system.

\section{RECOMMENDATION}

For future research in large system it is better to make MPPT controller for each group to track maximum power point faster.

\section{REFERENCES}

Belghith, O.B., L. Sbita and F. Bettaher, 2016. MPPT design using PSO technique for photovoltaic system control comparing to fuzzy logic and P\&O controllers. Energy Power Eng., 8: 349-366.

Clerc, M. and J. Kennedy, 2002. The particle Swarm-explosion, stability and convergence in a multidimensional complex space. IEEE Trans. Evol. Comput., 6: 58-73.

Eldahab, Y.E.A., N.H. Saad and A. Zekry, 2017. Enhancing the tracking techniques for the global maximum power point under partial shading conditions. Renewable Sustainable Energy Rev., 73: 1173-1183.

Goetzberger, A. and V. Hoffmann, 2005. Photovoltaic Solar Energy Generation. Springer, Berlin, Germany, ISBN:3-540-23676-7, Pages: 235.
Goud, J.S. and R. Kalpana, 2007. Optimal sizing of hybrid power supply system for telecommunication BTS load to ensure reliable power at lower cost. Proceedings of the 2017 International Conference on Technological Advancements in Power and Energy (TAP Energy), December 21-23, 2017, IEEE, Kollam, India, ISBN:978-1-5386-4022-7, pp: 1-6.

Hossam, K., A.R. Mikhail, I.M. Hafez and W.R. Anis, 2016. Optimum design of PV systems for BTS in remote and urban areas. Intl. J. Sci. Technol. Res., 5: 355-363.

Kamran, M., M. Mudassar, M.R. Fazal, M.U. Asghar and M. Bilal et al., 2018. Implementation of improved Perturb and observe MPPT technique with confined search space for standalone photovoltaic system. J. King Saud Univ. Eng. Sci., 2018: 1-11.

Kazimierczuk, M.K., 2008.Pulse-WidthModulatedDC-DC Power Converters. John Wiley and Sons, New Delhi, India, ISBN: 9780470694657, Pages: 808.

Khaliq, B.A. and A.L. Mahmood, 2015. Power load optimization for a remote area BTS site using MPPT algorithms. J. Inf. Sci. Comput. Technol., 4: 318-325.

Selmi, T., M. Abdul-Niby and A. Davis, 2014. P and O MPPT Implementation using MATLAB/Simulink. Proceedings of the 2014 9th International Conference on Ecological Vehicles and Renewable Energies (EVER), March 25-27, 2014, IEEE, Monte-Carlo, Monaco, ISBN:978-1-4799-3787-5, pp: 1-4.

Talukder, S., 2011. Mathematicle modelling and applications of particle swarm optimization. Master Thesis, School of Engineering, Blekinge Institute of Technology, Karlskrona, Sweden. 